PREPARED FOR THE U.S. DEPARTMENT OF ENERGY, UNDER CONTRACT DE-AC02-76CH03073

PPPL-3723

PPPL-3723

UC-70

\author{
Edge Turbulence Imaging \\ on NSTX and Alcator C-Mod
}

by

S.J. Zweben, R.A. Maqueda, J.L. Terry, B. Bai, C.J. Boswell, C.E. Bush, D. D'Ippolito, E.D. Fredrickson, M. Greenwald, K. Hallatschek,

S. Kaye, B. LaBombard, R. Maingi, J. Myra, W.M. Nevin, B.N. Rogers, D.P. Stotler, J. Wilgen, and X.Q. Xu

July 2002
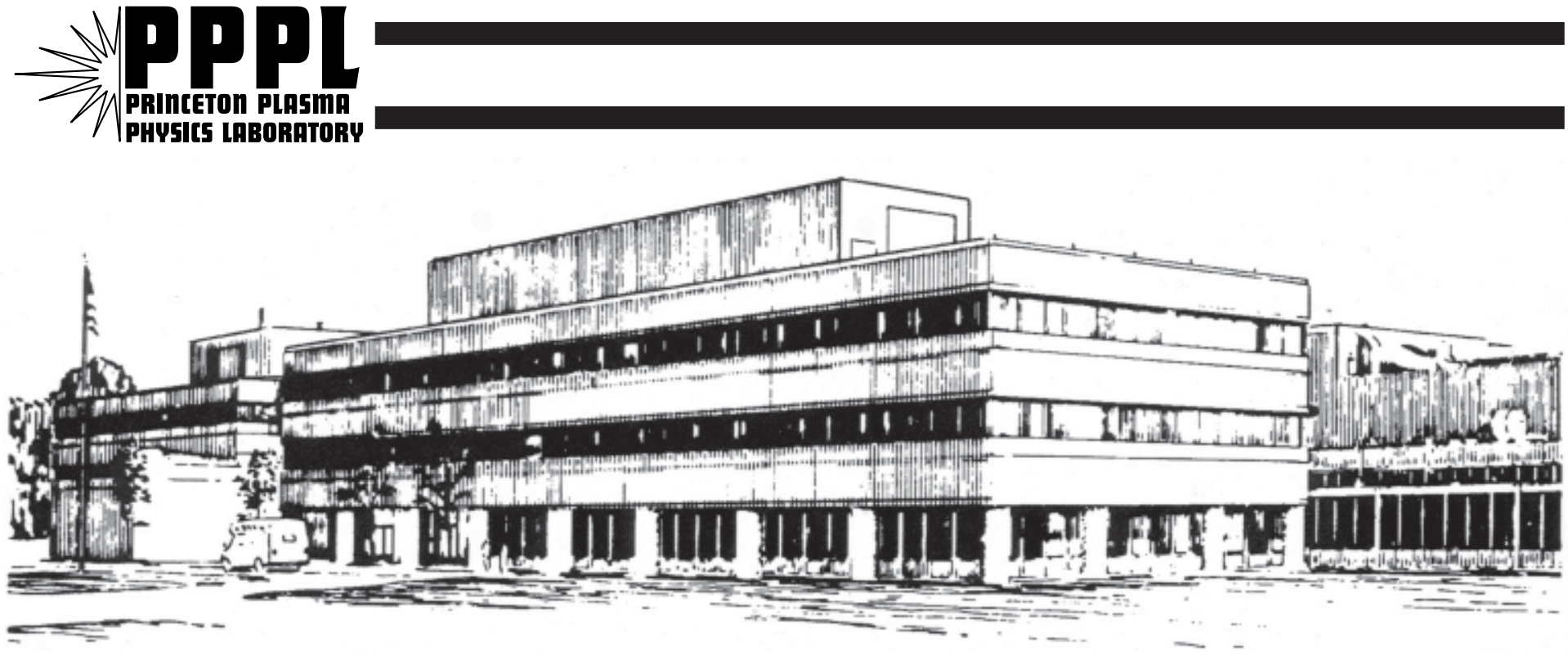

PRINCETON PLASMA PHYSICS LABORATORY PRINCETON UNIVERSITY, PRINCETON, NEW JERSEY 


\section{PPPL Reports Disclaimer}

This report was prepared as an account of work sponsored by an agency of the United States Government. Neither the United States Government nor any agency thereof, nor any of their employees, makes any warranty, express or implied, or assumes any legal liability or responsibility for the accuracy, completeness, or usefulness of any information, apparatus, product, or process disclosed, or represents that its use would not infringe privately owned rights. Reference herein to any specific commercial product, process, or service by trade name, trademark, manufacturer, or otherwise, does not necessarily constitute or imply its endorsement, recommendation, or favoring by the United States Government or any agency thereof. The views and opinions of authors expressed herein do not necessarily state or reflect those of the United States Government or any agency thereof.

\section{Availability}

This report is posted on the U.S. Department of Energy's Princeton Plasma Physics Laboratory Publications and Reports web site in Fiscal Year 2002. The home page for PPPL Reports and Publications is: http://www.pppl.gov/pub_report/

DOE and DOE Contractors can obtain copies of this report from:

U.S. Department of Energy

Office of Scientific and Technical Information

DOE Technical Information Services (DTIS)

P.O. Box 62

Oak Ridge, TN 37831

Telephone: (865) 576-8401

Fax: (865) 576-5728

Email: reports@adonis.osti.gov

This report is available to the general public from:

National Technical Information Service

U.S. Department of Commerce

5285 Port Royal Road

Springfield, VA 22161

Telephone: 1-800-553-6847 or

(703) 605-6000

Fax: (703) 321-8547

Internet: http://www.ntis.gov/ordering.htm 


\title{
Edge Turbulence Imaging on NSTX and Alcator C-Mod*
}

\author{
S.J. Zweben ${ }^{1}$, R.A. Maqueda ${ }^{2}$, J.L. Terry ${ }^{3}$, B. Bai ${ }^{3}$, C.J. Boswell ${ }^{3}$, C. E. Bush ${ }^{4}$, D. D'Ippolito ${ }^{5}$,
} E.D. Fredrickson ${ }^{1}$, M. Greenwald ${ }^{3}$, K. Hallatschek ${ }^{6}$, S. Kaye ${ }^{1}$, B. LaBombard ${ }^{3}$, R. Maingi ${ }^{4}$, J.

Myra $^{5}$, W.M. Nevins ${ }^{7}$, B.N. Rogers ${ }^{8}$, D.P. Stotler ${ }^{1}$, J. Wilgen ${ }^{4}$, X.Q. Xu

${ }^{1}$ Princeton Plasma Physics Laboratory, Princeton, NJ 08543, USA

${ }^{2}$ Los Alamos National Laboratories, Los Alamos, NM 87545, USA

${ }^{3}$ MIT Plasma Science and Fusion Center, Cambridge, MA 02139, USA

${ }^{4}$ Oak Ridge National Laboratory, Oak Ridge, TN 37831, USA

${ }^{5}$ Lodestar Research Corp, Boulder, CO 80301 USA

${ }^{6}$ Max-Plank-Institut fuer Plasmaphysik, D-85748 Garching, Germany

${ }^{7}$ Lawrence Livermore Laboratory, Livermore CA 94550, USA

${ }^{8}$ Dartmouth University, Hanover, NH 03755, USA

\section{Introduction:}

Edge turbulence images have been made using an ultra-high speed CCD camera on both NSTX and Alcator C-Mod. In both cases the $\mathrm{D}_{\alpha}$ or HeI $(587.6 \mathrm{~nm})$ line emission from localized deuterium or helium gas puffs was viewed along a local magnetic field line near the outer midplane. Fluctuations in this line emission reflect fluctuations in $n_{e}$ and/or $T_{e}$ through the atomic excitation rates, which can be modeled using the DEGAS-2 code. The 2-D structure of the measured turbulence can be compared with theoretical simulations based on 3-D fluid models.

\section{Gas Puff Imaging Diagnostic:}

The diagnostic set-up and first results from "gas puff imaging" (GPI) have been presented elsewhere [1-3]. In this paper we discuss images which were made using an ultrahigh speed Princeton Scientific Instrument CCD camera with a gating time of $10 \mu \mathrm{sec}$ per frame for NSTX and $4 \mu \mathrm{sec}$ per frame for C-Mod. These images clearly show the effects of edge turbulence on the light emission from these neutrals. If the fluctuations in electron density and temperature are in phase, as expected theoretically [4-6] and seen with Langmuir probes [7], then these 2-D images are at least qualitative representations of the space-time structure of these fluctuating fields. Analysis of the atomic excitation rates in these edge plasmas using DEGAS-2 shows that near the peak of the $\mathrm{D}_{\alpha}$ light emission in C-Mod, the local emissivity varies as $S \propto n^{0.6} \mathrm{~T}_{\mathrm{e}}^{0.5}$ [8], and near the peak of the light emission of $\operatorname{HeI}(587.6 \mathrm{~nm})$ in NSTX the local emissivity varies as $S \propto \mathrm{n}^{0.7} \mathrm{~T}_{\mathrm{e}}^{0.5}$. Details concerning the GPI diagnostic technique and its interpretation will be described in [9]. 


\section{Images from NSTX and Alcator C-Mod:}

A typical set of 28 sequential images of edge turbulence in NSTX taken with a HeI $(587.6 \mathrm{~nm})$ filter viewing a $\mathrm{He}$ gas puff near the outer midplane is shown in Fig. 1. The framing rate is 100,000 frames/sec and the exposure time for each frame is $10 \mu \mathrm{sec} / \mathrm{frame}$. The viewing area is $\approx 30 \mathrm{~cm} \times 15 \mathrm{~cm}$ in each frame, with the magnetic separatrix running approximately from the upper left to the lower right corner and the He gas puff and outer wall toward the lower left corner. This discharge (\#108164) is an Ohmic plasma with $\mathrm{I}_{\mathrm{p}}=0.8$ MA, $B_{0}=3.0 \mathrm{kG}$, a line averaged density of $\mathrm{n} \approx 3 \times 10^{13} \mathrm{~cm}^{-3}$ and an aspect ratio $A=1.3$. Qualitatively similar images were obtained in a variety of Ohmic and L-mode discharges using either He puffs viewed with a $587.6 \mathrm{~nm}$ filter or $D_{2}$ puffs viewed with a $D_{\alpha}$ filter.

A typical set of 12 sequential images of edge turbulence in Alcator C-Mod taken with a $D_{\alpha}(656.2 \mathrm{~nm})$ filter viewing a $\mathrm{D}_{2}$ gas puff near the outer midplane is shown in Fig. 2. The framing rate is 250,000 frames/sec and the exposure time for each frame is $4 \mu \mathrm{sec}$. The viewing area is $\approx 6 \mathrm{~cm} \times 6 \mathrm{~cm}$, with the magnetic separatrix running approximately vertically through the center of the image and the $\mathrm{D}_{2}$ gas puff and outer wall toward the left. This discharge (\#1010720006) is an Ohmic plasma with $\mathrm{I}_{\mathrm{p}}=0.95 \mathrm{MA}, \mathrm{B}_{\mathrm{o}}=53 \mathrm{kG}$, and a line averaged density of $\mathrm{n} \approx 3 \times 10^{14} \mathrm{~cm}^{-3}$ with an aspect ratio $\mathrm{A}=3.2$. Qualitatively similar images were obtained in a variety of Ohmic and L-mode discharges using either $\mathrm{D}_{2}$ puffs viewed at in $\mathrm{D}_{\alpha}$ or He puffs viewed with a $587.6 \mathrm{~nm}$ filter.

Both Fig. 1 and Fig. 2 show show complex patterns which vary randomly in time and space. The timescale for these variations is typically $\approx 20-30 \mu \mathrm{sec}$ in NSTX and $\approx 10-20 \mu \mathrm{sec}$ in C-Mod, corresponding to the autocorrelation time of the light emission fluctuations at a point in these images. The spatial scale for these variations is $\approx 3-7 \mathrm{~cm}$ in NSTX and $\approx 0.6$ $1.2 \mathrm{~cm}$ are C-Mod, which are typical of density turbulence correlation lengths in such devices. The frequency spectrum of the GPI light emission fluctuations in C-Mod closely matches the frequency spectrum of ion saturation current fluctuations in a Langmuir probe at that radius [3].

The only qualitative change in these images occurs during the ELM-free H-mode in NSTX, when the GPI light emission can become highly localized within a $\approx 2-3 \mathrm{~cm}$ wide radial band just inside the separatrix. This is most likely due to edge profile steepening in $\mathrm{H}$ mode, which causes the He line emission to narrow compared with its $\approx 10 \mathrm{~cm}$ wide radial extent in Ohmic and L-modes plasmas (as in Fig. 1). This narrowing is not seen during $\mathrm{H}$ modes in C-Mod, most likely because the edge density is higher in C-Mod and the neutral 
gas does not penetrate into the steep gradient region, but remains largely with the SOL where the turbulence does not change significantly during $\mathrm{H}$-mode.

\section{Comparison with Theory and Simulation:}

In principle the GPI results can be directly compared with numerical simulations of the 2-D structure of edge turbulence. However, raw images such as shown in Figs. 1 and 2 are sensitive to both electron density and temperature fluctuations (see Sec. 2), and also possibly to neutral density fluctuations due to radial "shadowing" [8]. Therefore rigorous comparisons should be made by either converting the raw images into actual density or temperature distributions, or (more easily) by converting the theoretical simulations into images of the expected GPI light emission patterns using a neutral transport and atomic physics code. The latter approach is being developed for interpreting the 2-D spatial structure using the time-independent DEGAS 2 code [8].

However, as a first approximation we can tentatively assume that the space-time structure of the raw images is similar to that of the edge turbulence itself [3]. Under this assumption, the most significant difference between the edge turbulence in NSTX and CMod is the spatial size of the "blobs" (i.e. localized maxima of the light emission), which appear to be $\mathrm{L}_{\mathrm{B}} \approx 5 \mathrm{~cm}$ in NSTX and $\mathrm{L}_{\mathrm{B}} \approx 1 \mathrm{~cm}$ in C-Mod. These scales are roughly consistent with the drift-wave-like trend seen previously as $\mathrm{k}_{\perp} \rho_{\mathrm{s}} \approx 0.1[10]$ (within a factorof-two), since $\rho_{\mathrm{s}} \approx 0.03 \mathrm{~cm}$ in C-Mod and $\rho_{\mathrm{s}} \approx 0.3 \mathrm{~cm}$ in NSTX, with $\left\langle\mathrm{k}_{\perp}\right\rangle \approx 3 / \mathrm{L}_{\mathrm{B}}$.

From a theoretical perspective, the size scale of edge turbulence may be related to the resistive ballooning mode scale length [11], which for C-Mod is $\mathrm{L}_{\mathrm{o}} \approx 0.2 \mathrm{~cm}$ and for NSTX roughly $\mathrm{L}_{\mathrm{o}} \approx 2 \mathrm{~cm}$, while the $\mathrm{SOL}$ turbulence may be driven by flute-like interchange modes [12]. However, it is difficult to explain the size scale based on linear instability theory since these structures, in particularly the "blobs" [13], are highly non-linear.

[1] R.J. Maqueda et al, Rev. Sci. Inst. 72, 931 (2001)

[2] J.L. Terry, et al, J. Nucl. Mat. 290, 757 (2001)

[3] S.J. Zweben et al, Phys. Plasmas 9, 1981 (2002)

[4] B.N. Rogers et al, Phys, Rev. Lett. 81, 4396 (1998)

[5] X.Q. Xu et al, Phys. Plasmas 7, 1951 (2000)

[6] K. Hallatschek, A. Zeiler, Phys. Plasmas 7, 2554 (2000)

[7] M.A. Meier et al, Phys. Rev. Lett. 87, 085003 (2001)

[8] D. Stotler et al, submitted to J. Nucl. Mat. (2002)

[9] R. Maqueda et al, to be submitted to Rev. Sci. Inst. (2002)

[10] A.J. Wootton et al, Phys. Fluids B2, 1844 (1989); M. Endler, J. Nucl. Mat. 266-269, 84 (1999)

[11] B. Kurzan et al, Plasma Physics and Cont. Fusion 42, 237 (2000)

[12] A. Huber, A.V. Nedospasov et al, J. Nucl. Mat. 266-269, p.546 (1999)

[13] D. D'Ippolito et al, Phys. Plasmas 9, 222 (2002)

* Work supported by USDOE Contracts \# DE-AC02-76CHO3073 and DE-FC02-99ER54512 


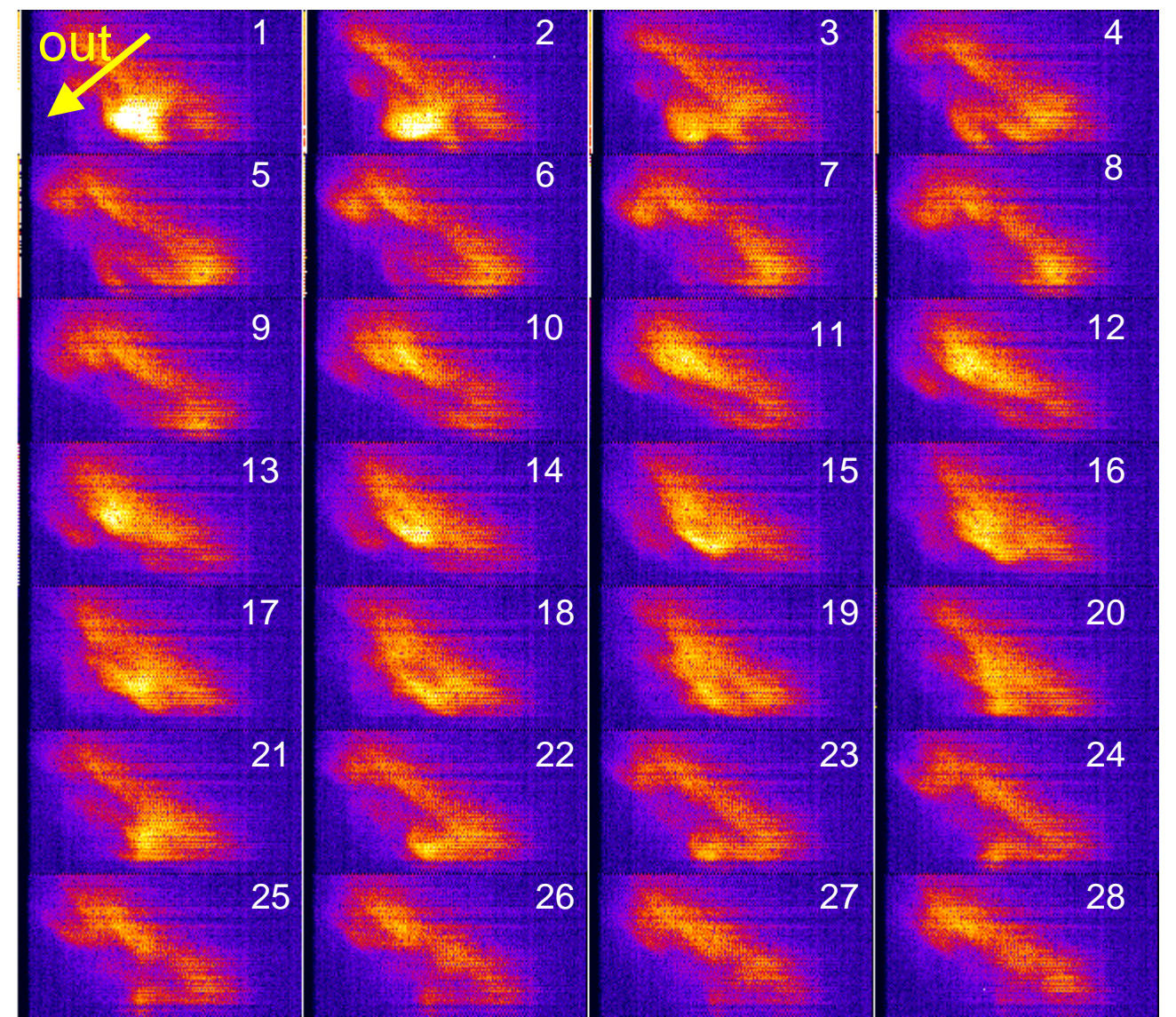

Fig. 1: Edge turbulence images from NSTX at 100,000 frames/sec showing a region $\approx 30$ $\mathrm{cm} \times 15 \mathrm{~cm}$ near the outer midplane with the outer wall toward the lower left corner.
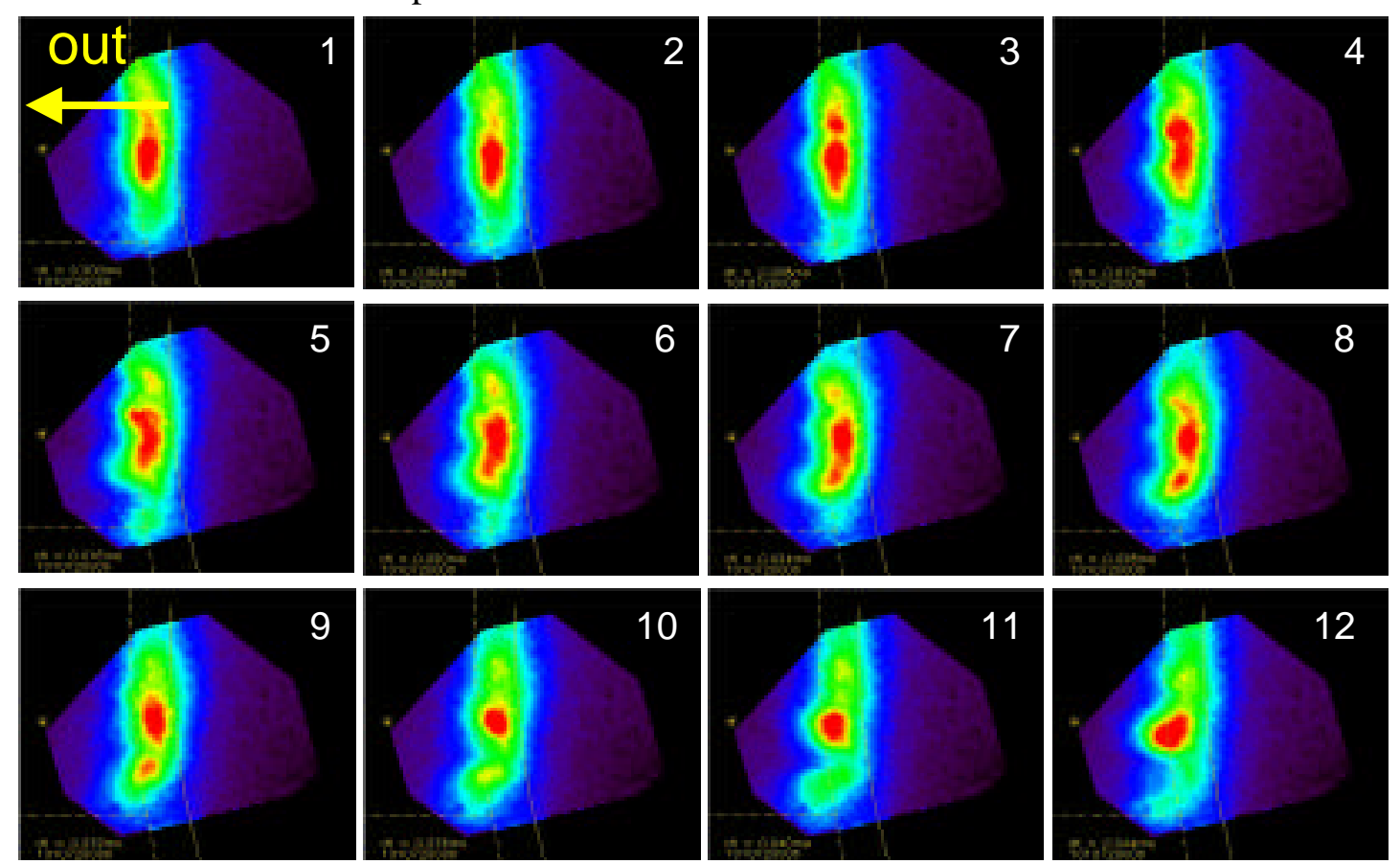

Fig. 2 - Edge turbulence images from Alcator C-Mod at 250,000 frames/sec showing a region $\approx 6 \mathrm{~cm} \times 6 \mathrm{~cm}$ near the outer midplane with the outer wall toward the left. 


\section{External Distribution}

Plasma Research Laboratory, Australian National University, Australia

Professor I.R. J ones, Flinders University, Australia

Professor J oão Canalle, Instituto de Fisica DEQ/IF - UERJ , Brazil

Mr. Gerson O. Ludwig, Instituto Nacional de Pesquisas, Brazil

Dr. P.H. Sakanaka, Instituto Fisica, Brazil

The Librarian, Culham Laboratory, England

Library, R61, Rutherford Appleton Laboratory, England

Mrs. S.A. Hutchinson, JET Library, England

Professor M.N. Bussac, Ecole Polytechnique, France

Librarian, Max-Planck-Institut für Plasmaphysik, Germany

J olan Moldvai, Reports Library, MTA KFKI-ATKI, Hungary

Dr. P. Kaw, Institute for Plasma Research, India

Ms. P.J . Pathak, Librarian, Insitute for Plasma Research, India

Ms. Clelia De Palo, Associazione EURATOM-ENEA, I taly

Dr. G. Grosso, Instituto di Fisica del Plasma, Italy

Librarian, Naka Fusion Research Establishment, J AERI, J apan

Library, Plasma Physics Laboratory, Kyoto University, J apan

Research Information Center, National Institute for Fusion Science, J apan

Dr. O. Mitarai, Kyushu Tokai University, J apan

Library, Academia Sinica, Institute of Plasma Physics, People's Republic of China

Shih-Tung Tsai, Institute of Physics, Chinese Academy of Sciences, People's Republic of China

Dr. S. Mirnov, TRINITI, Troitsk, Russian Federation, Russia

Dr. V.S. Strelkov, Kurchatov Institute, Russian Federation, Russia

Professor Peter Lukac, Katedra Fyziky Plazmy MFF UK, Mlynska dolina F-2, Komenskeho Univerzita, SK-842 15 Bratislava, Slovakia

Dr. G.S. Lee, Korea Basic Science Institute, South Korea

Mr. Dennis Bruggink, Fusion Library, University of Wisconsin, USA

Institute for Plasma Research, University of Maryland, USA

Librarian, Fusion Energy Division, Oak Ridge National Laboratory, USA

Librarian, Institute of Fusion Studies, University of Texas, USA

Librarian, Magnetic Fusion Program, Lawrence Livermore National Laboratory, USA

Library, General Atomics, USA

Plasma Physics Group, Fusion Energy Research Program, University of California at San Diego, USA

Plasma Physics Library, Columbia University, USA

Alkesh Punjabi, Center for Fusion Research and Training, Hampton University, USA

Dr. W.M. Stacey, Fusion Research Center, Georgia Institute of Technology, USA

Dr. J ohn Willis, U.S. Department of Energy, Office of Fusion Energy Sciences, USA

Mr. Paul H. Wright, Indianapolis, Indiana, USA 
The Princeton Plasma Physics Laboratory is operated by Princeton University under contract with the U.S. Department of Energy.

\author{
Information Services \\ Princeton Plasma Physics Laboratory \\ P.O. Box 451 \\ Princeton, NJ 08543
}

Phone: 609-243-2750

Fax: 609-243-2751

e-mail: pppl_info@pppl.gov

Internet Address: http://www.pppl.gov 